¿Qué llega de la historiografía académica a la historiografía escolar? Una exploración en torno a la temática de la última dictadura en la escuela secundaria

María Paula González

páginas / año 13 - n 32 Mayo-Agosto / ISSN 1851-992X/ 2021

http://revistapaginas.unr.edu.ar/index.php/RevPaginas

DOI: $10.35305 /$ rp.v13i32.505

\title{
¿Qué llega de la historiografía académica a la historiografía escolar? Una exploración en torno a la temática de la última dictadura en la escuela secundaria ${ }^{1}$
}

\author{
What comes from academic historiography to school \\ historiography? An exploration around the last dictatorship in high \\ school
}

\author{
María Paula González \\ Universidad Nacional de General Sarmiento, \\ Consejo Nacional de Investigaciones Científicas y Técnicas (Argentina) \\ mpgonzal@campus.ungs.edu.ar ${ }^{2}$ \\ https://orcid.org/0000-0003-0357-2365
}

\begin{abstract}
Resumen
Este trabajo se interroga sobre los diálogos entre historiografía académica y escolar en torno al abordaje de la última dictadura. A través del análisis de diseños curriculares vigentes, libros escolares y otros materiales didácticos de reciente edición explora las perspectivas de abordaje, los conceptos adoptados, así como las referencias académicas más recurrentes. En conjunto, muestra que la historiografía escolar se relaciona en grados variables de convergencias y distancias con el mundo académico por causa de los límites, intencionalidades, tiempos y lógicas que las diferencian y las aproximan. Además, el trabajo indica que, por un lado, la historiografía escolar utiliza ciertas perspectivas y estabiliza algunas referencias del mundo académico y, por otro, no presenta una conceptualización unívoca aun cuando expone un sólido consenso de condena a la última dictadura.
\end{abstract}

\section{Palabras Clave}

Historiograf通 académica; Historiograf通 escolar; Última dictadura; Escuela secundaria.

\footnotetext{
${ }^{1}$ Se retoma la noción de "historiografía escolar" propuesta por Rafael Valls (2012). Aunque el autor lo utiliza para analizar manuales escolares aquí se ha extendido su uso al considerar los diseños curriculares y otros materiales educativos que hoy participan en la enseñanza de la historia portando narrativas.

${ }^{2}$ Este artículo forma parte del trabajo desarrollado en el marco del Proyecto PICT 2017-1311 "La historia como disciplina escolar: transformaciones recientes en los saberes, materialidades y prácticas en el nivel secundario". Agradezco las agudas lecturas de Ernesto Bohoslavsky, Silvia Finocchio, Marina Franco y Daniel Lvovich sobre las versiones preliminares de este trabajo, así como los comentarios recibidos en oportunidad de presentar los avances en las Jornadas Interescuelas de Historia de 2019 y en el marco de las reuniones de trabajo del GRIDEH - PEH de la UNGS. Del mismo modo, mi gratitud a los/las evaluadores/as de la revista.

Esta obra está sujeta a la Licencia Reconocimiento-NoComercial-CompartirIgual 4.0 Internacional de Creative Commons. http://creativecommons.org/licenses/by-nc-sa/4.0/

(cc) EY-NC-SA
} 


\title{
María Paula González
}

\begin{abstract}
This work asks about the dialogues between academic and school historiography around the approach of the last dictatorship. Through the analysis of current curricular designs, school books and other recently published teaching materials, she explores the approach perspectives, the concepts adopted as well as the most recurring academic references. Overall, it shows that school historiography is related to varying degrees of convergence and distance with the academic world due to the limits, intentions, times and logics that differentiate and approximate them. In addition, the work indicates that, on the one hand, school historiography uses certain perspectives and stabilizes some references from the academic world and, on the other, it does not present a univocal conceptualization even though it exposes a solid consensus of condemnation of the last dictatorship.
\end{abstract}

\section{Keywords}

Academic historiography; School Historiography; Last dictatorship; High school.

\section{Introducción}

En 1991, Silvia Finocchio lanzaba un interrogante en el primer número de la revista Entrepasados con el art通ulo titulado "Una reflexión para los historiadores: “qué llega de nuestra producción a la escuela media?". A través del análisis de planes de estudio del siglo XX y de libros de texto escolares editados hasta fines de los años '80, la autora indicaba que la historia -como asignatura escolar- constitu唒 el paradigma de la inmovilidad, la desactualización y la escasa significatividad de contenidos. Según Finocchio, tal situación era consecuencia de dos factores. Por un lado, el escaso contacto entre el campo de la investigación histórica y el de la formación docente (en especial, durante la segunda mitad del siglo XX). Por otro, el carácter formal de adhesión de la historia escolar al liberalismo poltitico que no permitió el planteo de problemas en esa asignatura (lo que en contrapartida le posibilitó sobrevivir en el curr政ulo al acomodarse a las más diversas coyunturas pol团icas). ${ }^{3}$

Casi treinta años después, aquellos factores han cambiado notablemente. De una parte, los historiadores han participado intensamente en la elaboración de libros de texto escolares y variados materiales didácticos, as? como han incidido en las propuestas curriculares. De otra, la historia escolar se presenta hoy como una asignatura para problematizar el pasado. ${ }^{4}$

Pero aún con todos esos cambios, la pregunta acerca del v鲠culo entre historiograf通 académica e historiograf escolar sigue vigente y precisa una respuesta actualizada. Sigue vigente porque la enseñanza no solo ha constituido en el pasado "la piedra angular de la historia como conocimiento" (Le Goff, 2016: 11) sino porque en el

\footnotetext{
${ }^{3}$ Ese diagnóstico era compartido por otros especialistas (Lanza, 1993, Devoto, 1992, Braslavsky, 1991) al tiempo que contrastaba con la situación de otras disciplinas escolares -como física, literatura y educación cívica- que manifestaban un mayor dinamismo (Finocchio, 1989).

${ }^{4}$ Sobre la participación de los historiadores en currículo y libros de textos en momentos de la reforma educativa de los 90 véase De Amézola (2005) y Romero (2004). En relación con los cambios en los objetivos de la historia como disciplina escolar: Finocchio (1999), De Amézola (2008), González (2018).
} 


\section{¿Qué llega de la historiografía académica a la historiografía escolar? Una exploración en torno a la temática de la última dictadura en la escuela secundaria}

presente varias áreas de historia de universidades nacionales se vinculan fuertemente con la formación de profesores (en grado y posgrado). También, porque la historiograf绝 escolar se erige como un importante canal de difusión de la investigación historiográfica académica. Sigue vigente, además, porque la historia en la escuela asume una función c⿴囗玉 ica que hoy implica aportar a la formación de ciudadanos cr 团icos comprometidos con la democracia, función que también cumple la historia producida en la academia. ${ }^{5}$

Asimismo, se trata de un interrogante que precisa una respuesta actualizada en relación con el tema que aqu?lse ha seleccionado, esto es, la última dictadura militar. $Y$ es que si bien se han producido trabajos sobre ese recorte temático que han examinado diseños y libros de textos, algunos lo han hecho con otras preguntas -por ejemplo, el impacto de las pol团icas de memoria- (Acosta, 2015) y otros con un corpus diferente, es decir, con libros escolares que respond仍n a diseños curriculares que ya no están en vigencia (Zysman, 2015; De Amézola et al, 2012; De Amézola, 2011; Alonso, 2006; De Amezola, 2006; Alonso \& Rubinzal, 2004; Reta \& Pescader, 2002, entre otros). ${ }^{6}$ Pero más allá de las mutaciones de la historia escolar en los últimos años -por medio de nuevos diseños curriculares y publicación de renovados materiales didácticos- que justificar $\mathbf{X}_{n}$ un nuevo estudio como el aqu?propuesto, se debe considerar también la notable expansión de la historia reciente como campo académico -visible en la cantidad y variedad de investigaciones-.7

Por cierto, cabe aclarar que los rasgos que asume la historiograf伍 escolar -en lo referido a la última dictadura- no puede comprenderse sólo por la contribución de la historiograf通 académica sino también por el aporte de otras ciencias sociales, de otros campos culturales (cine, literatura), por el impacto de procesos más vastos tales como los cambios pol ticos, los vaivenes judiciales y las construcciones memoriales as? como por la impronta de las prácticas escolares y docentes (Finocchio, 2007; De Amézola, 2011; González, 2019). No obstante, este escrito se concentra en analizar e interpretar qué llega de la historiograf通 académica a la historiograf通 escolar por la relevancia de este vinculo. ${ }^{8}$

\footnotetext{
${ }^{5}$ Aunque sin referir a "la formación de ciudadanos", varios historiadores han señalado el aporte de una mirada crítica y reflexiva que puede hacer la historiografía académica. Véase por ejemplo, Franco (2012:33) cuando la autora indica cuál puede ser el aporte de su investigación sobre orden interno, violencia y "subversión" en Argentina entre 1973 y 1976.

6 Por ejemplo, De Amézola (2011) y De Amézola et al (2012) realizaron el análisis sobre seis manuales escolares editados entre 1997 y 2004, es decir, de la oferta editorial que respondía a los diseños de la Ley Federal de Educación de 1993 mientras que actualmente se encuentra vigente la Ley de Educación Nacional de 2006.

7 Para un panorama de la producción académica en torno al pasado reciente, pueden verse los balances presentados por Águila y otras (2018), Franco (2018), Franco \& Lvovich (2017), Bohoslavsky (2016), Oberti \& Pittaluga (2016), Bohoslavsky et al (2010)

${ }^{8}$ Resulta oportuno indicar que existen otros trabajos que han tomado esta misma inquietud, aunque para otros temas, como la Revolución de mayo (Lewkowicz \& Rodríguez, 2016). En ese trabajo, las autoras analizan la narrativa de la historia escolar en producciones realizadas dos coyunturas: en torno al centenario y al bicentenario. Así, constatan que en el segundo momento se había producido una fuerte renovación que incorporaba las matrices explicativas más actualizadas de la historiografía
} 
Tal exploración se ha realizado a partir de variadas fuentes: los diseños curriculares vigentes hoy (tanto a nivel nacional ${ }^{9}$ como de la provincia de Buenos Aires ${ }^{10}$ ), un conjunto de libros de texto escolares ${ }^{11}$, as? como una selección de materiales producidos por el Ministerio de Educación a través del Programa Educación y Memoria ${ }^{12}$ y del Canal Encuentro ${ }^{13}$. Desde luego, se trata de un conjunto diverso de fuentes: algunas corresponden a la prescripción pol团ica normativa -legislación y diseños-; otras a una propuesta didáctica estatal -los materiales producidos por el ministerio de Educación-; y otras a la propuesta editorial. Y es en esa diversidad que podemos pensar la historiograf通 escolar puesto que se trata de una construcción realizada desde distintos espacios, intencionalidades y lógicas.

Por ello, el trabajo analizará la historiograf通 escolar para indicar, en primer lugar, quiénes son sus autores; en segundo lugar, para apuntar las perspectivas de abordaje de la última dictadura; en tercer término, para observar los conceptos adoptados para explicarla y definirla, y en último lugar para mostrar las referencias académicas que se manifiestan con mayor grado de recurrencia.

En contraste con el diagnóstico de los años '90 del siglo XX citado al inicio del art臥ulo, se mostrará que la historiograf通 escolar -referida a la última dictadura- está en diálogo con la historiograf凫 académica aunque en grados variables de convergencia y distancia a causa de los l lanites, intencionalidades, tiempos y lógicas que las diferencian y las aproximan. Además, el trabajo indica que, por un lado, la historiograf㢬 escolar utiliza ciertas perspectivas y estabiliza algunas referencias del mundo académico y, por otro, no presenta una conceptualización un đoca aun cuando expone un sólido consenso de condena a la última dictadura.

académica. Del mismo modo, De Amézola (2011) indica que es preciso el permanente diálogo entre la historia enseñada y la investigada precisamente para el mismo tema que aquí se trabaja: última dictadura.

9. Núcleos de Aprendizajes Prioritarios. Ciencias Sociales. Campo de formación general del ciclo orientado de Educación Secundaria (ME, 2012); Núcleos de Aprendizajes Prioritarios. Ciencias Sociales. Ciclo básico de Educación Secundaria (ME, 2011); Núcleos de Aprendizajes Prioritarios Ciencias Sociales. EGB/Nivel Medio 8/1 y 9/2 años (MECyT, 2006)

10. Programa de Definición del Diseño Curricular del Nivel Polimodal de Provincia de Buenos Aires. Espacio Curricular Historia (PBA-DGCyE, 2005): Historia, 5to año (PBA-DGCyE, 2011); Historia, 6to año (PBA-DGCyE, 2012).

11. Los libros analizados son siete (de cinco editoriales diferentes) y fueron seleccionados ya que resultan los más utilizados por docentes de historia según se desprende de otras fuentes analizadas en la investigación marco de la que surge este artículo. Los libros son de las editoriales Estrada (2011), Kapelusz (2013), Santillana (2011 y 2017), Maipue (2012) y Aique (2000 y 2013) Para facilitar la lectura del artículo los hemos citado con el nombre de la editorial que es como usualmente se los nombra en el mundo escolar.

12. "Pensar la dictadura: terrorismo de Estado en Argentina. Problemas, respuestas y propuesta para su enseñanza" (ME, 2010). "A treinta y cinco años del golpe, educación y memoria. Cuadernillo para secundaria" (ME, 2011b).

13. Capitulo "1976" de la serie Años decisivos (producido en 2012), y los episodios 21 "La dictadura I: Economía y represión" y 22 "La dictadura II: del golpe a Malvinas" de la serie Argentina Siglo XX: Historia de un país (ambos del 2007). Esta selección se justifica en que se trata de los materiales producidos por Canal Encuentro más utilizados por los profesores de historia de secundaria tal como ha documentado la investigación de Buletti (2019). También un estudio general llevado ha demostrado el uso de esos materiales por parte de docentes de nivel medio (Abramowski \& Igarzábal, 2011). 


\section{¿Qué llega de la historiografía académica a la historiografía escolar? Una exploración en torno a la temática de la última dictadura en la escuela secundaria}

\section{Autores}

Como se dijo, este estudio se basa en un conjunto diverso de fuentes: prescripciones pol团ico-normativas, propuestas didácticas de origen estatal y libros de texto del mundo editorial.

A pesar de tratarse de un conjunto heterogéneo de materiales lo que s?es común a esta historiograf通 escolar es que sus autores son graduados universitarios en historia, muchos de ellos con cargos docentes en universidades nacionales, institutos superiores de formación docente y algunos, además, investigadores del CONICET. ${ }^{14}$ Es decir que, como primera constatación, son los historiadores académicos quienes se pueden identificar como los autores de la historiograf通 escolar. No son mundos ajenos sino, muy por el contrario, estrechamente conectados en esta dimensión.

Además se trata de historiadores que trabajan en diálogo con colegas de otros campos, esto es, con investigadores en otras ciencias sociales (econom旸, pol身ica,

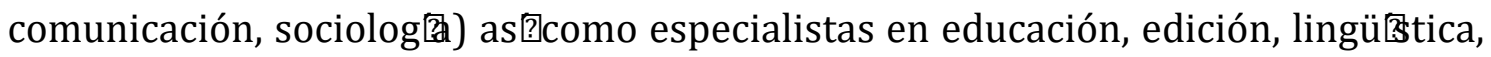
etc. De ello se desprende la segunda constatación, esto es que, como para el caso del campo académico, el pasado reciente es abordado de modo interdisciplinario en las prescripciones y sugerencias dirigidas al mundo escolar.

\section{Perspectivas}

En términos generales, al explorar la historiograf通 escolar se destacan dos grandes modos de mirar la última dictadura: uno de carácter temporal y otro de tipo espacial. En relación a lo temporal, la perspectiva que aparece -aunque con matices- es la del golpe de 1976 como hito que abre un nuevo ciclo. Tal periodización que coloca a la fecha del último golpe de Estado como "referencia semiautomática de una experiencia histórica sustancialmente distinta y aislable" (Franco \& Lvovich, 2017: 204) responde -según esos autores- al relato construido en la posdictadura. Hace

\footnotetext{
${ }^{14}$ Autores de la oferta editorial: María Inés Tato, Juan Pablo Bubello, Ana María Castello, Esteban Campos (Estrada) Andrea N. Andújar, Benjamín F. Carabajal, Verónica Giordano, Karin V. Grammático, Gustavo C. Guevara, María Morichetti, Elena C. Scirica, Verónica Seghezzo, Guillermo D. Vissani y Cecilia Wahren (Santillana de 2017). Maria E. Alonso y Enrirque C. Vázquez (Aique) Victoria Basualdo, Diego Bentivegna, Roberto Elisalde, Virginia Iris Fernández, Ana Laura Montani, Mariana Pérez, Florencia Racana, Analía Rizzi, Damián Rizzi, Ceciclia Romana, Valeria Snitcofsky (Kapelusz). El único libro de autoría individual es el de Editorial Maipue y su autora es Teresa Eggers-Brass. Autores o asesores de los audiovisuales analizados: Gabriel Di Meglio, Gustavo Álvarez, Marina Franco (episodios de la serie Historia de un país) Gustavo Álvarez, Marisa Baldasarre, Victoria Basualdo, Julio Djenderedjian, Martina Garategaray, Fernando Gómez, Marcelo Mariño, Leandro Morgenfeld Mariana Pérez, Sergio Pujol, Lucas Rebagliati (del episodio 1976 de la serie Años decisivos), Coordinadores, autores y revisores de los materiales del Programa Educación y Memoria (en las dos ediciones consultadas): María Celeste Adamoli, Matías Farías, Cecilia Flachsland, Emmanuel Kahan, Federico Lorenz, Pablo Luzuriaga, Roberto Pittaluga, Noelia Roger, Violeta Rosemberg, Edgardo Vannucchi.
} 


\section{María Paula González}

poco tiempo que esta lectura ha comenzado a ser revisada y relativizada por una parte de la historiografie académica, al colocar a la última dictadura en un arco temporal mayor y al discutir el binomio dictadura-democracia (por ejemplo, Pittaluga, 2010 y Franco, 2012).

Como se dijo, si bien esta división aparece con claridad en la historiograf通 escolar también se registran algunos indicios que, sin quebrar del todo tal periodización, proponen el análisis de antecedentes, cambios y continuidades del terrorismo de Estado en el per沼do previo que va de 1955 a $1976^{15}$ o incluso en algunos acontecimientos desde 1919. ${ }^{16}$

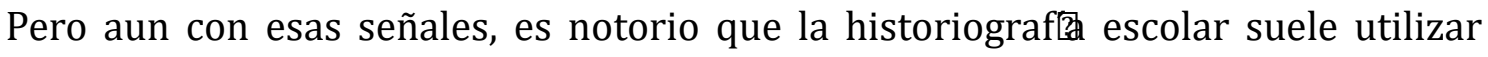
periodizaciones más taxativas (tanto para el tratamiento de la última dictadura como para otros temas). $\mathrm{Y}$ es que ellas permiten secuenciar contenidos dividiéndolos en unidades de trabajo como exige el cotidiano escolar. Desde luego,

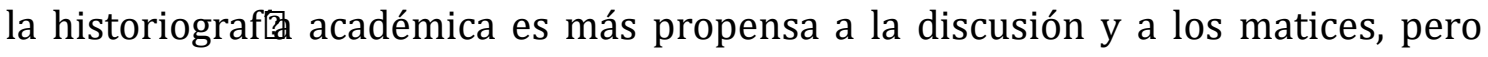
¿hasta qué punto es posible evitar el uso de ciertas marcas temporales en la enseñanza de la historia? 0, en todo caso, ¿cómo ser 3 posible eludir sus efectos totalizantes? Al respecto, la necesidad de "cortar la historia en rebanadas" (Le Goff, 2016) es parte del esfuerzo por construir un saber transmisible a un público mayor no especializado.

Ahora bien, aunque haya necesidades didácticas para trasmitir un contenido, no se debe soslayar que trabajar con perí⿴囗十 dos como compartimentos estancos no sólo es resultado de una decisión didáctica: se trata de una proposición pol俰ica y memorial para la lectura del pasado y para la formación ciudadana y no se deber vista sus consecuencias en la formación de los imaginarios sociopol团icos de los jóvenes. En otras palabras, tanto las luchas de memoria como el mandato escolar de "generar en los/as alumnos/as reflexiones y sentimientos democráticos y de defensa del Estado de Derecho y la plena vigencia de los Derechos Humanos"17 han forzado una mirada retrospectiva que coloca a la dictadura como algo aislable y único en lugar de pensar prácticas autoritarias y represivas incluso en gobiernos constitucionales.

En relación con lo espacial, la segunda perspectiva que se percibe en la historiograf辸 escolar actual, aunque de modo dispar y con ciertos l国nites, es la de pensar la dictadura en el contexto latinoamericano. Esto ha sido subrayado por la

\footnotetext{
${ }^{15}$ Es el caso del libro escolar editado por Aique (2000) que en la página en que se explican "los grupos de tareas y los centros de detención clandestinos" y se propone discutir (en una ventana lateral) en torno a la pregunta "¿errores, excesos o plan sistemático? All@os autores sugieren una actividad con las siguientes preguntas: $i$ Qué antecedentes hubo en el periodo 1955-1976 de la pol俰ica denominada terrorismo de Estado? ¿Qué diferencias se pueden establecer entre las politicas represivas de la última dictadura militar y la aplicada por los reg解enes autoritarios anteriores? (Aique, 2000: 285) 16“Sugerimos que los estudiantes busquen información sobre esos acontecimientos: la Semana Trágica (1919); las huelgas de la Patagonia (1921); los bombardeos sobre civiles en la Plaza de Mayo (1955); los fusilamientos de José León Suárez (1956); la Noche de los Bastones Largos (1966) y la Masacre de Trelew (1972). En un segundo momento, proponemos que respondan las siguientes preguntas: ¿Por qué esos hechos pueden ser considerados antecedentes del terrorismo de Estado? ¿Qué similitudes y qué diferencias tienen con esta experiencia?" (ME, 2010: 53).

${ }^{17}$ Ley Nacional de Educación, 26206/06, artículo 92.
} 


\section{¿Qué llega de la historiografía académica a la historiografía escolar? Una exploración en torno a la temática de la última dictadura en la escuela secundaria}

historiograf通 académica que ha indicado tanto la relevancia como la tendencia creciente de esta mirada (Franco \& Iglesias, 2011; Bohoslavsky et al, 2010).

Tal perspectiva es prescrita oficialmente en los NAP ${ }^{18}$ donde se presenta primero la escala latinoamericana para luego introducir la nacional. Del mismo modo, tal mirada es retomada en el diseño curricular provincial de $5^{\circ}$ año puesto que -en conjunto y no solo para el tema dictadura- ese diseño está organizado desde una periodización latinoamericana y no desde la argentina. ${ }^{19} \mathrm{Al}$ mismo tiempo, es retomado por los materiales didácticos oficiales ${ }^{20}$ al igual que se refiere en uno de los tres audiovisuales explorados ${ }^{21}$.

Respecto a los libros de textos analizados, la situación es más dispar. Y es que algunos solo desarrollan la escala nacional (como Kapelusz y Aique) mientras que quienes toman los lineamientos de los NAP y el diseño provincial s?introducen la escala latinoamericana (Estada y Santillana).

Pero aunque la tendencia creciente es a pensar la última dictadura argentina en diálogo con la escala latinoamericana, surge la inquietud de si realmente estamos ante un modo de ver y leer la última dictadura. En algunos casos (cuando los libros escolares presentan cap团ulos separados para las escalas latinoamericana y la nacional), América latina parece quedar más como marco general (sin indicar conexiones con la historia argentina) o como espacio para casos paradigmáticos (por ejemplo, la Revolución cubana) que como perspectiva general de interpretación y un lugar desde el cual pensar la Argentina.

Frente a este balance, no habr魚 que perder de vista que la historia como disciplina escolar tuvo una fuerte impronta nacionalista y eurocéntrica durante buena parte del siglo XX (Finocchio, 2007 y De Amézola, 2008) y que la inclusión de la historia latinoamericana estuvo sujeta a notables vaivenes en los últimos años. En relación con esto último, Di Croce y Garriga (2011) indican que hacia 1983 se vivió cierta "primavera latinoamericana" que rápidamente se desvaneció con la Ley Federal de 1993 en la que, sin ser totalmente borrada, Latinoamérica perdió centralidad. Con la Ley Nacional de 2006 -y sus diseños derivados aqu? analizados- esta escala

\footnotetext{
${ }^{18}$ En el caso de los NAP se indica como contenido: "El análisis del modelo económico neoliberal implementado en América Latina en las últimas décadas del siglo XX, priorizando los casos donde se articula con el terrorismo de Estado, en el marco de la crisis de 1973 y de la reconfiguración del sistema capitalista" (ME, 2012: 7)

19“Golpes y terrorismo de Estado en América Latina. Agotamiento del modelo de industrialización por sustitución de importaciones. La crisis económica de Cuba: las medidas de emergencia y la supervivencia de la Revolución Cubana. (PBA, DGCyE, 2011: 20)

${ }^{20}$ En el material "Pensar la dictadura..." (ME, 2010) tal perspectiva se desarrolla en el capítulo 3 "La dictadura en el mundo" con una serie de apartados titulados: ¿Qué fue la Doctrina de Seguridad Nacional?, ¿Qué relaciones pueden establecerse con las demás dictaduras que se implementaron en Latinoamérica?, ¿En qué consistió el Plan Cóndor?

21 "Para 1976, tanto Argentina como Chile, Uruguay, Paraguay y Bolivia se encuentran bajo el gobierno de dictaduras militares. Desde comienzos de la década de los 60, representantes de las Fuerzas Armadas de esos países asisten a la Escuela de las Américas, organismo creado por el Gobierno de los Estados Unidos con el fin de entrenar a los ejércitos latinoamericanos en la lucha contra el comunismo" Historia de un país / La dictadura I: Economía y represión, 7:53 a 8:19.
} 


\section{María Paula González}

reaparece. Pero más allá de lo propiamente escolar, la historia latinoamericana -en el largo plazo- no ha tenido gran presencia en la educación superior, tanto en la formación de profesores como en la investigación historiográfica en la Argentina (De Amézola, 2015) aun cuando en los últimos años tal tendencia se ha revertido (Águila, 2012) y se han hecho esfuerzos por propiciar miradas no solo comparadas sino también conectadas que ayuden a descentrar la mirada de lo nacional a lo regional y superar desconexiones en el abordaje de procesos de largo (y ancho) alcance (Bohoslavsky \& Franco, 2020). En tal sentido, la historiograf通 escolar mostrar通 cierta convergencia con la académica. En otras palabras, el abordaje escolar de la perspectiva latinoamericana para la última dictadura estar峺 en relación con el derrotero en el ámbito académico.

\section{Referencias}

En conexión con las perspectivas antes señaladas, se han relevado las referencias bibliográficas del mundo académico presentes en la historiograf通 escolar. ${ }^{22}$ En términos generales, la producción más citada en los diseños curriculares, materiales educativos y libros de texto son, por un lado, aquellas que han tenido un afán más hol[3tico y de divulgación; por otro, aquellas que fueron pioneras en establecer ciertas discusiones e interpretaciones en torno a la última dictadura como proceso histórico (y hoy se han convertido en "clásicos"); y, finalmente, las que reflexionaron e investigaron algunos aspectos puntuales en los años 2000 (de la historia reciente como pasado y como campo de estudios).

En relación con las obras más generales -que durante bastante tiempo fueron las únicas disponibles según indican Franco y Lvovich (2017)-, la historiograf通 escolar referencia el trabajo de Luis Alberto Romero (en sus diversas ediciones) y los publicados en las colecciones de Sudamericana -los tomos coordinados por James y Suriano- y de Paidós -la obra de De Riz y la de Novaro y Palermo-.23

Por su parte, las obras precursoras de los años '80 y los '90 (que no surgen dentro del marco de la historiograf解) resultan ser también las referencias más estables y

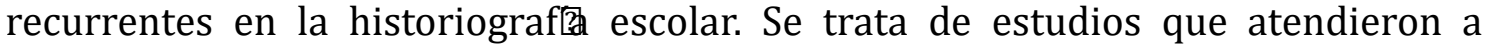
problemas tales como el autoritarismo, la transición democrática, las transformaciones sociales producidas por el régimen, las caracter represivo, la emergencia de los movimientos de derechos humanos, entre otros. Entre estas, se citan los trabajos de Acuña, Cavarozzi, Duhalde, O’Donnell, Villarreal

\footnotetext{
${ }^{22}$ Se excluyó de este análisis los materiales audiovisuales ya que los mismos no utilizan citas de autoría por tratarse de un discurso de divulgación (lo que no impide ver referencias implícitas).

${ }^{23}$ Romero, L.A. (1994) "Breve historia contemporánea de la Argentina", Buenos Aires: Fondo de Cultura Económica. James, D. (dir.) (2003). Violencia, proscripción y autoritarismo (1955-1976). Tomo IX Nueva Historia Argentina. Buenos Aires: Sudamericana. Suriano, J. (dir.) (2005) Dictadura y democracia (1976-2001). Tomo X Nueva Historia Argentina. Buenos Aires: Sudamericana. De Riz, L. (2000) La política en suspenso: 1966-1976. Buenos Aires: Paidós. Novaro, M. y Palermo, V. (2003). La dictadura militar (1976/1983) Del golpe de Estado a la restauración democrática. Buenos Aires: Paidós
} 


\section{¿Qué llega de la historiografía académica a la historiografía escolar? Una exploración en torno a la temática de la última dictadura en la escuela secundaria}

y Jelin. ${ }^{24}$ En particular, el concepto de "semidemocracia" propuesto por Cavarozzi es el que sirve de base para la presentación de los procesos históricos de la segunda mitad del siglo XX argentino en el diseño de $5^{\circ}$ año de la Provincia de Buenos Aires. ${ }^{25}$ En esta senda, y a modo de ejemplo, la referencia excluyente sobre la cuestión de la Iglesia católica durante la dictadura es la obra de Emilio Mignone. ${ }^{26}$ Del mismo modo, los tempranos trabajos producidos por el campo de la econom son citados en las fuentes consultadas -por ejemplo, Aspiazu, Basualdo y Khavisse, Schvarzer entre otros-. 27

En relación con los trabajos desarrollados en los años 2000, la historiograf烼 escolar repite referencias en relación con tópicos espec đificos tales como historia reciente, memoria, historia y memoria, historia oral. Se trata de las obras de Vezzetti, Crenzel, Jelin, Schwarzstein, Franco y Lev国.28

Si se observan las referencias expl值itas que aparecen en el cuerpo del texto de los manuales escolares, se distinguen tres: la noción de "reestructuración social" de Juan Villareal (citado en Santillana, 2011: 182 y Santillana, 2017: 182), la idea de Pilar Calveiro de que "generar terror a través de los secuestros era parte del plan de generar terror en toda la sociedad" (citado en Santillana, 2011: 179 y Santillana, 2017: 179) y la referencia a Daniel Feierstein sobre genocidio (citado por Maipue, 2012: 120).29

\footnotetext{
${ }^{24}$ Acuña, C. y Smulovitz, C. (1995) Militares en la transición argentina: del gobierno a la subordinación constitucional. En AAVV, Juicio, castigos y memorias. Derechos humanos y justicia en la política argentina. Buenos Aires: Nueva Visión. Cavarozzi, M. (1997): Autoritarismo y democracia (19551996). La transición del Estado al mercado en la Argentina. Buenos Aires: Ariel. Duhalde, E (1983) El estado terrorista argentino. Buenos Aires: El Caballito. Duhalde, E (1999): El estado terrorista argentino, Quince años después, una mirada crítica. Buenos Aires: Eudeba. O’Donnell, G. (1987) Democracia en la Argentina: Micro y Macro. En Oszlak, 0. (comp.) "Proceso", crisis y transición democrática. Buenos Aires: CEAL. Villarreal, J. (1985). Los hilos sociales del poder. En AAVV. Crisis de la dictadura argentina. Buenos Aires: Siglo XXI. Jelin, E. (2002) Los trabajos de la memoria. Buenos Aires: Siglo XXI. Jelin, E. (1995) La política de la memoria: el movimiento de derechos humanos y la construcción democrática en la Argentina. En AAVV, Juicio, castigo y memorias. Derechos humanos y justicia en la política argentina. Buenos Aires: Nueva Visión.

25Véase PBA-DGCyE, 2011: 13.

${ }^{26}$ Mignone, E. (1986) Iglesia y dictadura. El papel de la Iglesia a la luz de sus relaciones con el régimen militar. Buenos Aires: Ediciones del Pensamiento Nacional.

${ }^{27}$ Aspiazu, D. et al (1986). El nuevo poder económico en la Argentina. Buenos Aires: Legasa. Schvarzer, J. (1996) La industria que supimos conseguir. Una historia político-social de la industria argentina. Buenos Aires: Planeta.

${ }^{28}$ Crenzel, E. (2008). La historia política del Nunca Más. La memoria de las desapariciones en la Argentina. Buenos Aires: Siglo XXI. Jelin, E. (2002) Los trabajos de la memoria. Buenos Aires: Siglo XXI. Schwarzstein, D. (2001) Una introducción al uso de la Historia Oral en el aula. Buenos Aires: Fondo de Cultura Económica. Franco, M \& Levín, F. (comps) (2007). Historia reciente. Perspectivas y desafíos para un campo en construcción. Buenos Aires: Paidós. Vezzetti, H. (2003). Pasado y Presente. Guerra, dictadura y sociedad en la Argentina, Buenos Aires: Siglo XXI. Las obras de Franco \& Levín y de Schwarzstein aparecen citados también en el diseño curricular de $6^{\circ}$ año de historia de provincia de Buenos Aires.

${ }^{29}$ Santillana (2011 y 2017) utiliza en esas dos ocasiones la cita textual, un recurso poco usual ya que el discurso de los manuales se caracteriza por la despersonalización (por la que se lo libera de las marcas de autor烼, tan propias de los espacios académicos). Más contrastante aún resulta la opción
} 


\section{María Paula González}

Visto en perspectiva, puede afirmarse que la historiograf通 escolar "estabiliza" ciertas obras del mundo académico que son también las más estables y menos discutidas del campo -tal como constatan Franco y Lvovich (2017)- y que, a la vez, son las que abordan los temas menos polémicos: democracia, crimen estatal, derechos humanos, etc.

As包 se tratar通 entonces de referencias que resultan más operativas a la disciplina escolar -como ya se dijo para el caso de las periodizaciones- porque son los que parecen responder mejor a sus rasgos y fines: proveer explicaciones generales en los tiempos y ritmos escolares (acotados, de múltiples asignaturas, mediados por otros tantos aspectos y problemas no espec(ficamente disciplinares) y destinado a un público no especializado como son los jóvenes a los que se los pretende formar pol团icamente.

También a partir de estas referencias "estabilizadas", el análisis muestra que existe un diálogo entre historiograf通 escolar e historiograf通 académica (incluyendo las producciones de otras ciencias sociales) aunque en especial con las elaboradas en los años ‘80 y ‘90 y no con las más actuales.

Ante esta última evidencia ser通 fácil concluir que la historiograf通 escolar siempre va a la zaga de la historiograf通 académica. Sin embargo, en los años '90, la historiograf通 escolar -tomando referencias de otras ciencias sociales y otras prácticas culturales- se hizo cargo del pasado reciente antes que la historiograf色 académica lo abordara (González, 2014). Pero ahora que el campo dedicado al pasado reciente se ha expandido notablemente resulta visible que lo tiempos académicos son diferentes a los escolares: tanto en lo que hace a la elaboración de los diseños curriculares (los que están en vigencia y se analizan aqu?lson de 2011 y 2012) como a la producción de libros de texto y los materiales ministeriales (véase las fechas de publicaciones) está claro que el mundo escolar tiene una temporalidad más lenta que la profusa y sistemática producción académica, que, además, en el caso particular de la historia reciente atravesó un crecimiento exponencial. ${ }^{30}$ Los NAP nacionales y los diseños provinciales tienen casi diez años de vigencia. Las editoriales casi no ha renovado sus producciones y las que lo han hecho no han modificado la sección correspondiente a dictadura. ${ }^{31}$ Los materiales ministeriales analizados fueron producidos entre 2010 y 2011. All los tiempos normativos, pol团icos y editoriales que impactan en la historiograf局 escolar. Los tiempos normativos dependen de la capacidad pol团ica de lograr consensos o mayor通s para la transformación de la legislación y diseños y, por otra

de Maipue (2012) -utilizar citas al pie como en un paper académico- lo que constituye una excepción en el conjunto.

${ }^{30}$ Sobre ese crecimiento, véanse las estadísticas presentadas por Franco y Lvovich (2017).

${ }^{31}$ Es el caso de la oferta más reciente de Santillana -de 2017- no se modifica la sección dedicada a la última dictadura y se repite la narrativa y las referencias de la edición de 2011 a excepción del número de nietos recuperados. 


\section{¿Qué llega de la historiografía académica a la historiografía escolar? Una exploración en torno a la temática de la última dictadura en la escuela secundaria}

parte, no podr風n ser sometidos a la transformación permanente. ${ }^{32}$ Por otra parte, los tiempos de las pol团icas públicas y de elaboración de materiales -tanto escritos como audiovisuales- que demandan meses y años de preparación, producción, edición, divulgación, etc. Finalmente, los tiempos editoriales que responden sobre todo a factores comerciales y hacen que las empresas no revisen o actualicen lo que funciona en el mercado sino que sencillamente agreguen páginas para avanzar en el tiempo e incluir los últimos gobiernos democráticos (aunque esos contenidos no estén prescritos en la normativa).

\section{Conceptos}

La historiograf通 escolar muestra diversos conceptos para referir al per政do 19761983: “dictadura c⿴ico- militar", "terrorismo de Estado" y “genocidio”. Se trata de categor la historiograf序 académica ha planteado debates recientes que reflejan discusiones no solo disciplinares sino, sobre todo, poltiticas y memoriales.

La noción "dictadura c⿴囗玉 ico-militar" se instaló en los discursos pol团icos oficiales (de los gobiernos kirchneristas) y en el vocabulario de los organismos de derechos humanos hacia fines de los años 2000 (Montero, 2016). Se trata de una

lectura novedosa sobre la naturaleza del régimen militar, sobre la composición de los actores que participaron de él, y sobre el rol de la sociedad civil -en particular, de los sectores de poder como la Iglesia, la justicia, los empresarios, los partidos pol团icos, los sindicatos, pero también de profesionales, periodistas, intelectuales y entidades o instituciones públicas- en la instauración y consolidación del proyecto autoritario iniciado el 24 de marzo de 1976 (Montero, 2016: 55)

Aun cuando se trata de una noción con gran aceptación, algunos académicos han propuesto una discusión en torno a ella -por ejemplo, Marina Franco (2016)-. Según esta autora, la evolución total del sistema, sus li sobresalientes indican que en esos aspectos siguen correspondiendo a un predominio de las Fuerzas Armadas. Por eso, y "aun cuando el término dictadura militar sea pobre, decepcionante e igualmente insuficiente para dar cuenta de la complejidad de lo sucedido" (Franco, 2016: 89) se lo prefiere frente a otros que, buscando dar cuenta de participaciones y complicidades, terminan desdibujando el rasgo militar que fue definitorio del régimen.

En contraste, y antes de que se plantearan estas discusiones en la historiograf通 académica, una parte de la historiograf通 escolar adoptó la noción "c国ico-militar" al tiempo que se consolidaba en una parte de la opinión pública, en las intervenciones de los organismos de derechos humanos y en los discursos oficiales. As 自 se registra

\footnotetext{
${ }^{32}$ Obsérvese que las transformaciones educativas nacionales más importantes de los últimos tiempos (leyes Federal de Educación de 1993 y de Educación Nacional de 2006) se lograron bajo gobiernos peronistas.
} 
un uso generalizado en la normativa, de manera dispar en los libros, y de modo indirecto en los materiales audiovisuales analizados.

En efecto, mientras que en los NAP de 2006 y 2011 se hablaba de "dictadura militar", en los dirigidos al ciclo superior editados en 2012 se la introduce la noción de "golpe c⿴ico-militar". Ese cambio se repite en los diseños de la provincia de Buenos Aires. Mientras que en el diseño de 2005 se hablaba de "dictadura militar" (PBA-DGCyE, 2005: 183), en los aprobados para $5^{\circ}$ año en 2011 se introducen las nociones de

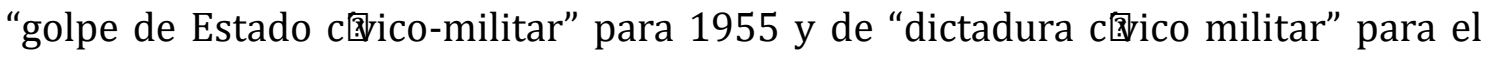
perindo 1976-1983 -aunque no se utiliza ninguna de esas acepciones para la autodenominada "Revolución Argentina"-. En el caso del diseño de $6^{\circ}$ año aprobado en 2012, se indica al 24 de marzo como "golpe de Estado c⿴囗玉 la noción de "golpe c⿴囗十

En los libros escolares se repiten transformaciones similares, incluso en los de una misma editorial y de los mismos autores. Es el caso de Aique: mientras que en la obra publicada por Alonso y Vázquez en el año 2000 se optaba por el término "dictadura militar", en la aparecida en 2013 se trabaja con la noción de "dictadura c $\mathbf{*}$ ico militar". De todas maneras, en una mirada general, la utilización es dispar: aparece en los libros de Aique (2013) y Maipue (2012) aunque en este último caso como "golpe c国ico-militar a la educación" -tal como prescribe el diseño curricular de Historia de $6^{\circ}$ año de provincia-. En contrapartida, no es utilizada por las producciones de Santillana (2011 y 2017), Estrada (2011) ni Kapelusz (2013). En el caso de los materiales audiovisuales seleccionados para el análisis, se indica el "aval" y el "apoyo" de diversos sectores de la sociedad aunque no se cita directamente la noción. ${ }^{33}$

Una cuestión conexa a la noción de dictadura c⿴囗玉 acentuar el v国culo entre represión dictatorial e imposición de un modelo económico. Y aun cuando hace tiempo que aquella relación fue señalada -por ejemplo, por Walsh, en su carta abierta a la Junta Militar en $1977^{34}$ y por Duhalde en 1983 (1999) en su estudio sobre el Estado Terrorista35-, comenzó a ser utilizada recurrentemente en discursos de los organismos de derechos humanos, as ? parte de la prensa y sus investigaciones derivadas sobre todo desde los años de los gobiernos kirchneristas. ${ }^{36}$ En contrapartida, varios trabajos académicos han

\footnotetext{
${ }^{33}$ Por ejemplo, en el episodio 21 de la serie "Historia de un país, Argentina siglo XX" el guion indica: "el proyecto de los militares cuenta con el apoyo de muchos civiles, grupos financieros, grandes empresarios, terratenientes, y gran parte de la jerarquía de la Iglesia católica avala las políticas de la dictadura y justifica todas las acciones necesarias para llevarlas a cabo".

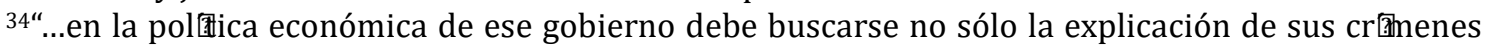
sino una atrocidad mayor que castiga a millones de seres humanos con la miseria planificada" https://www.cels.org.ar/common/documentos/CARTAABIERTARODOLFOWALSH.pdf

${ }^{35}$ En su primera edición del "Estado terrorista argentino", Duhalde señalaba que el proyecto económico exigió "la implantación del terror para hacer posible su instauración" aunque advertía que no se hacía cargo de su análisis. Véase el prólogo a la primera edición reproducido en la segunda edición (Duhalde, 1999: 203)

36Por ejemplo, Verbitsky y Bohoslavsky (2013: 12) afirman que "la denominación "dictadura militar" va cayendo en desuso, en favor de otras más complejas y aproximadas a la realidad de lo que fue un bloque cívico, militar, empresarial y eclesiástico".
} 


\section{¿Qué llega de la historiografía académica a la historiografía escolar? Una exploración en torno a la temática de la última dictadura en la escuela secundaria}

discutido fuertemente esa vinculación como causal (por ejemplo, Vezzetti, 200237) mientras que otros han invitado a pensar la distinción entre proyecto, proceso y resultados (Franco, 2016). ${ }^{38}$

Al explorar la historiograf通 escolar, la correlación entre represión e implantación de un modelo económico neoliberal es ambigua: se la indica alternativamente como causal, como v魚culo y como consecuencia. En los NAP se introduce la idea de relación entre dictadura y aplicación de un modelo económico y social neoliberal pero con matices interesantes de ser subrayados. Mientras que en las versiones de 2006 y 2011 se indica trabajar con "la última dictadura y su relación con la Guerra Fr屷 y la aplicación de un modelo económico y social neoliberal” (ME, 2006: 25 y ME,

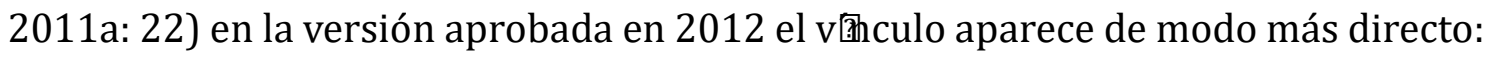
“la comprensión del golpe c国ico-militar de 1976 y del Terrorismo de Estado como plan sistemático para destruir a las organizaciones populares y disciplinar a la sociedad, creando las condiciones de implementación del modelo económico neoliberal (ME, 2012: 7). ${ }^{39}$

Por su parte, en los materiales educativos el v国culo también es dispar. En algunos libros de texto escolares desarrollan esa vinculación (por ejemplo, Aique, 2000 y $2013^{40}$ y más fuertemente Maipue, 2012 ${ }^{41}$ ). En otros, se indican actividades que

\footnotetext{
37"cuando se dice y se repite que la masacre argentina fue necesaria para implantar un modelo económico que requer $\mathbf{3}$ liquidar, exactamente de esa manera, cualquier oposición, no se ofrece, en verdad, ninguna evidencia para ello. Modelos económicos similares [...] han sido implantados en otros pa 3 es de América latina y el mundo sin un costo equivalente en vidas y en la degradación pol tica del Estado. El argumento presupone en verdad la idea de una excepcionalidad argentina y parece admitir que la intensidad y la violencia de la oposición civil a la intervención restauradora era de tal magnitud que sólo una masacre pudo permitir la estabilización del régimen militar [...] Pero no hay nada que corrobore esas tesis, salvo la fantas de que la Argentina se hallaba al borde de la revolución social" (Vezzetti, 2002: 161).

38"Que uno de los principales resultados de la dictadura haya sido el cambio en el régimen de acumulación y transformaciones regresivas estructurales no significa que ese haya sido su objetivo y proyecto fundamental y que defina la naturaleza del régimen. En otros términos, en muchas interpretaciones del per政do hay una tendencia a leer el proceso ex post, desde el presente: el consenso generalizado sobre el éxito de la poltica económica dictatorial para producir las transformaciones buscadas nos lleva a afirmar que ese era su principal objetivo" (Franco, 2016: 83)

${ }^{39}$ Las cursivas son mías.

${ }^{40}$ Este libro desarrolla la introducción del captitulo dedicado a dictadura como "Terrorismo de Estado y libre mercado" (Aique, 2000: 264) y como "Fundamentos ideológicos de la dictadura militar: terrorismo de estado y libre mercado (1976-1983) (Aique, 2013: 12)

${ }^{41}$ “El golpe militar fue pergeñado con civiles que tenían intereses económicos bien claros: mayores ganancias para sus empresas, sea cual fuera la suerte del país. Contaban con el aliento de Estados Unidos para eliminar al Estado de Bienestar, e introducirnos en una etapa neoliberal. Los argumentos para deshacer las conquistas sociales, dejar de fomentar la industria nacional, prohibir las organizaciones que molestaran a su ideología, eran fútiles, un simple decorado para su avidez de ganancia: "lucha contra la subversión", "lucha contra la corrupción", "modernización de la economía", "ineficiencia del sector industrial", "inflación", "déficit fiscal", "deuda"..." (Maipue, 2012: 138) "El neoliberalismo -que adquiere características diferentes en distintos Estados- defiende el libre mercado capitalista, y a diferencia del liberalismo clásico, sí necesita del apoyo del Estado para sostener las políticas de los más fuertes. Había que disciplinar a la sociedad para lograrlo. Era necesario controlar a los empresarios nacionales, a los sindicalistas, y a todos los que luchasen en contra de ese modelo" (Maipue, 2012: 139)
} 
invitan a que los estudiantes reflexionen sobre ella. ${ }^{42}$ Finalmente, en otros materiales se desarrolla la cuestión de un nuevo modelo económico y la reestructuración social sin subrayar la vinculación necesaria entre la represión y neoliberalismo sino más bien como un proceso o consecuencia (por ejemplo, ME, 201043; Santillana, 2011 y 2017; Estrada, 2011). En el caso de los materiales audiovisuales, la relación se enuncia de modo directo. ${ }^{44}$

La noción "terrorismo de Estado" -derivada de la noción "Estado terrorista" sistematizada por Eduardo Luis Duhalde en 1982-83 durante su exilio en Madridfue adoptada tempranamente por los organismos de derechos humanos en Argentina para caracterizar el accionar represivo de la dictadura y contrarrestar el relato militar de "guerra sucia". Tal concepto es el que más claramente ha sido adoptado por la historiograf通 escolar: aparece en todos los documentos oficiales, as ? como en todas las fuentes editoriales y materiales audiovisuales analizados. Mayoritariamente, su uso se restringe al per $\mathbf{b}$ do post 1976 aunque en algunos casos -especialmente en materiales didácticos y algunos libros de texto escolares- se extiende hacia los años previos. ${ }^{45}$ En algunos libros escolares se menciona la obra de Duhalde (1999) que incluso -en ocasiones- se suma como cita o referencia bibliográfica expl fitita en ventanas laterales (Aique, 2000: 269 y 2013: 16).

Respecto a este concepto, algunos historiadores han propuesto (muy recientemente) su discusión puesto que su uso parece provocar la cristalización de algunas representaciones, esto es, la idea de un Estado monol tico, con una única forma de acciones y dispositivos represivos (los clandestinos) frente a una sociedad también monol tica e indiferenciada v䢞tima del disciplinamiento social (Águila, 2016). En el caso de la historiograf通 escolar el uso del término terrorismo de Estado convive con apartados dedicados a diversas formas de control, censura, imposición del miedo y acciones psicológicas aunque sin señalar las prácticas legales y cuasilegales como reclama la citada autora. Al mismo tiempo, esa noción se conecta con otras páginas dedicadas a las diversas actitudes sociales de diferentes actores sociales frente a la dictadura. En balance, si bien la historiograf通 escolar no presenta una sociedad monol 团ica es cierto que tiende a subrayar la excepcionalidad del

\footnotetext{
42"Establezcan relaciones entre el modelo económico de la dictadura y la conformación del terrorismo de Estado" (Kapelusz, 2013: 383)

${ }^{43}$ Esto aparece en el apartado ¿Cuál fue el proyecto económico-social de la dictadura? ¿Cómo se vinculó con la estrategia represiva? (ME, 2010: 34-35)

44"A partir de marzo de 1976, las Fuerzas Armadas argentinas instalan en el país un régimen de terrorismo de Estado. El secuestro, la tortura y el asesinato de ciudadanos civiles es usado por los miembros de la Junta Militar como herramienta principal para imponer su plan de gobierno, que incluye una profunda transformación política, especialmente económica". Historia de un país, episodio 21 "La dictadura I: Economía y represión", 15:59 a 16:23. En el caso del episodio "1976" de la serie Años decisivos, se indica "La dictadura militar se dio a sí misma el nombre de "Proceso de reorganización nacional" y procuró perpetuarse en el poder. Sus objetivos eran lograr la disciplina de la sociedad e instalar un nuevo modelo económico [...]" 10:51 a 11:02

${ }^{45}$ Es el caso del libro editado por Maipue que introduce la noción de terrorismo de Estado al tratar la Masacre de Trelew de 1972 (pág. 101), la Triple A (pág. 110) y el Operativo Independencia (pág. 115). También, como se indicó notas al pie anteriores (13 y 14) algunos materiales proponen trabajar con "antecedentes" del terrorismo de Estado.
} 


\section{¿Qué llega de la historiografía académica a la historiografía escolar? Una exploración en torno a la temática de la última dictadura en la escuela secundaria}

terrorismo de Estado y su faz represiva (aun cuando -como se dijo en el apartado anterior- algunos materiales intentan marcar antecedentes)

Finalmente, el concepto "genocidio" -un término ciertamente muy complejo por sus implicancias jur dicas que fue apropiado por una parte de los organismos de derechos humanos ${ }^{46}$ - aparece de modo intermitente en la historiograf通 escolar. En efecto, no es utilizado por la normativa oficial (ni nacional ni provincial) para aludir a la última dictadura al tiempo que es indicada como una categor魚 en discusión por parte de los materiales editados por el Estado. ${ }^{47}$ En el caso de las propuestas editoriales, tal concepto aparece en las de Maipue (2012), Aique (2000 y 2013) y Kapelusz (2013), mientras que no es usado por Santillana (2011 y 2017) ni Estrada (2011). En el caso de Maipue (2012) se indica tal noción para hablar de la dictadura y se cita el trabajo de Feierstein (en nota al pie, algo inusual en los libros escolares). En el caso de Aique (2000 y 2013) también se utiliza para tratar "las cifras del genocidio" y para dar cuenta de la metodolog棫 de represión (Aique 2013: 32; Aique, 2000: 285).48 La propuesta de Kapelusz (2013: 383) lo utiliza en un subt娄ulo "represión y genocidio" pero sin desarrollar una definición. En las producciones audiovisuales de Canal Encuentro aqu ?analizadas, este concepto tampoco aparece. En resumen, cuando "genocidio" aparece en la historiograf通 escolar se lo utiliza -en la mayor得 de los casos- al hablar o adjetivar a la represión y no al régimen como un todo.

Esta intermitencia en el uso de la categor emparenta con las discusiones dentro del campo académico. En algunos casos fue utilizado sin discusión (Romero, 1994) y luego descartado (Romero, 2012) ${ }^{49}$, en otro defendido como marco de interpretación que enfatiza lo represivo (Feierstein, 2007) y en otros rechazado por desdibujar el carácter pol团ico de la represión de la última dictadura (Sigal, 2001 y Vezzetti, 2002).

Visto en perspectiva, y en relación con los conceptos utilizados, resulta notorio que la historiograf鷵 escolar no depende en este punto de la historiograf通 académica -

\footnotetext{
46Para una visión de los debates y una discusión más amplia sobre esta categor勈, véase el trabajo de Alonso (2016)

${ }^{47}$ Bajo el t团ulo “¿Cómo deben ser considerados los cr 国menes de la dictadura?” se indica “El debate en torno a cómo caracterizar y/o definir los cr国nenes ejecutados por la última dictadura permanece abierto. Las distintas visiones y abordajes pueden sintetizarse en dos interpretaciones: aquellas que consideran las acciones criminales como un genocidio y aquellas que las caracterizan como una masacre organizada. Estas discusiones se desarrollan tanto en el campo jur dico como en el sociológico" (ME, 2010: 148)

48“El resultado de la aplicación de esta metodolog稀 por parte de las Fuerzas Armadas y policiales fue un genocidio, concretado a través del secuestro, la tortura y el asesinato de miles de personas"

${ }^{49}$ En el prefacio a la tercera edición de su obra "Breve historia contemporánea de la Argentina", Romero (2012: 11) indicó: "quiero subrayar un cambio menor pero completamente deliberado. En la versión original de este libro, inicié el cap团ulo dedicado a la última dictadura militar con un acápite que titulé

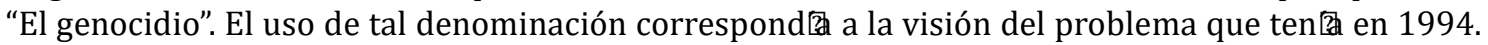
Más tarde aprend包que la calificación era impropia -no hab㘧 una cuestión de raza o etnia-, y que además oscurec俑 la naturaleza pol团ica de la represión. De modo que lo modifiqué por “El Estado terrorista"'".
} 


\section{María Paula González}

puesto que esas nociones derivan de luchas memoriales, pol团icas y jur como tampoco constituye una narrativa homogénea sino que conviven diversas nociones (incluso al interior de algunas fuentes analizadas). No obstante, esa diversidad permite -a la vez- mostrar una unidad: el sólido consenso de condena a la última dictadura. Esto resulta evidente en los modos de nombrar y explicar el perßo 76-83: dictadura militar, dictadura c⿴ico-militar, genocidio, terrorismo de Estado, e incluso cuando se indica "proceso de reorganización nacional" toda vez que se lo utiliza entre comillas y/o se advierte que se trató de una auto denominación. Si en los años '90 aún se pod魚n leer en los libros escolares que las décadas de los '70 y '80 hab得n sido años de "agresión y derrota de la subversión marxista” -tal como se defin河 en los contenidos de historia del programa de 1979- (Born, 2010) esto, definitivamente, no aparece en la oferta editorial actual.

Dicho esto, cabe indicar que, si bien resulta saludable que la historiograf通 escolar muestre que la condena a la última dictadura tiene alto consenso, en contrapartida, genera cierta inquietud que no exponga las diferentes narrativas y "luchas por la memoria" de la sociedad argentina -de las que solo se encuentran muy breves referencias en el libro de Santillana (2011: 188 y 2017: 188) y en el material "Pensar la dictadura" (ME, 2010: 149-ss)-. Sin omitir la condena a la dictadura, dar cuenta de esas "luchas por la memoria" en la sociedad argentina puede ser promisorio para la formación de los jóvenes, para que la defensa de los derechos humanos, la justicia y la memoria no sea una mera declamación sino una práctica reflexionada desde su inherente historicidad.

\section{A modo de cierre}

En s鲁tesis, ¿qué llega de la historiograf魚 académica a la historiograf通 escolar en torno a la última dictadura? Esta pregunta tiene -obviamente- varias respuestas. Llegan los historiadores. Llegan sus aportes más holæ̋ticos a la vez que más estables y menos discutidos. Llegan sus l limites frente a la fuerza de las narrativas memoriales y la potencia de las luchas pol团icas. Llega su estrecho diálogo con otras disciplinas. Llegan sus preguntas permeadas también por los debates sociales y las luchas pol团icas, por lo decible y escuchable.

Ahora bien, también se podr通 cambiar el eje y proponer otra interrogación: ¿qué es lo que no llega de la historiograf通 académica a la escolar? No llega toda su exponencial producción de los últimos años en muchos casos atomizada en estudios espec ficos de registro erudito. Y no llega -entre otras cosas- porque los tiempos de ambas historiograf通s resultan por demás desiguales. Tampoco llegan todos sus matices y problematizaciones porque las lógicas de ambas historiograf通s (hoy) son diferentes. Por un lado, porque la historiograf凷 escolar está dirigida a un público no experto y en formación. Por otro, porque se rige por una intencionalidad pedagógica que es más ética y pol团ica que académica.

En fin, como se dijo, los v鲠culos con la historiograf通 académica son apenas un aspecto de la historiograf通 escolar. No obstante, el diálogo entre ambas 


\section{¿Qué llega de la historiografía académica a la historiografía escolar? Una exploración en torno a la temática de la última dictadura en la escuela secundaria}

historiograf通s resulta relevante y deber蛹mos mantener la interrogación en torno a él. Y es que la exploración de esa pregunta puede ser un aporte mutuo. La historiograf通 escolar puede advertir que necesita de la académica para contar con herramientas más densas y complejas a la vez que menos complacientes para el análisis del pasado dirigidas a la formación pol tica de jóvenes generaciones. A su vez, la historiograf奥 escolar le puede señalar a la historiograf通 académica que resulta preciso que ésta ampl臣 y diversifique sus registros y lenguajes para una difusión más vasta de sus aportes de tal manera que alcancen al mundo educativo (y más allá) -sin desconocer que se necesitan espacios y experiencias que posibiliten tales producciones como las propiciadas por el Ministerio de Educación hasta 2015-. Esta amplificación y divulgación de sus avances le posibilitar涌 a la historiograf鮙 académica dar cuenta (una vez más) del v国culo entre historia y pol躯ica. Porque la educación, finalmente, es un acto pol团ico.

\section{Referencias}

Abramowski, A. \& Igarzábal, B. (2011). Uso y apropiación de las producciones de Canal Encuentro en las escuelas bonaerense. Universidad Pedagógica de Buenos Aires. Recuperado de: http://unipe.edu.ar/wpcontent/uploads/2012/07/Proyecto7encuentro.pdf

Acosta, J. (2015). Lecturas y libros de texto: la historia reciente en la escuela. Análisis de los manuales del nivel medio luego de la sanción de la Ley Nacional de Educación en 2006. Clío \& Asociados. La Historia Enseñada, (20), 149-161.

Águila, G. (2016) Violencia pol团ica, represión y terrorismo de estado: a propósito de algunas conceptualizaciones para definir el accionar represivo en la historia reciente argentina. En Flier, P. (coord.) Mesas de debate de las VII Jornadas de Trabajo sobre Historia Reciente. La Plata: Ediciones UNLP.

Águila, G. (2012) “¿Qué es ser un/a latinoamericanista? Los derroteros de la historia latinoamericana contemporánea en la Argentina” Anuario № 24 Escuela de Historia Revista Digital No $3 . \quad$ Recuperado de: https://anuariodehistoria.unr.edu.ar/index.php/Anuario/article/view/96/96

Águila, G. et al (comps.) (2018) La historia reciente en Argentina. Balance de una historiografía pionera en América Latina. Buenos Aires: Imago Mundi.

Alonso, L. (2016) Los usos del concepto de "genocidio" y el problema de la formación de categor en las disciplinas socio-históricas. En Flier, P. (coord.) Mesas de debate de las VII Jornadas de Trabajo sobre Historia Reciente. La Plata: Ediciones UNLP. 


\section{María Paula González}

Alonso, F. (2006). La dictadura militar argentina (1976-1983) en los textos de Ciencias Sociales e Historia para el tercer ciclo de la Educación General Básica. En Kaufmann, Carolina (dir.), Dictadura y educación. Los textos escolares en la historia argentina reciente (pp. 228-294). Buenos Aires: Miño y Dávila.

Alonso, F. \& Rubinzal, M. (2004). Memorias y representaciones. De Signos y Sentidos, $n$ ⒉ Cuadernos de la Universidad Nacional del Litoral.

Bohoslavsky, E. (2016). Cambios en la historiograf通 académica en Argentina (20012015). História da Historiografia: International Journal of Theory and History of Historiography, 9, 20. Recuperado de: https://www.historiadahistoriografia.com.br/revista/article/view/967/631

Bohoslavsky, E. et al (2010). Promesas y problemas de la historia reciente del Cono Sur (a modo de introducción). En Problemas de historia reciente del Cono Sur (pp. 1119, tomo I). Buenos Aires: Prometeo-UNGS.

Braslvasky, C. (1991). Los libros de texto en su contexto: Argentina 1975-1989. En Rieckenberg, M. (comp.). Latinoamérica: Enseñanza de la historia, libros de texto y conciencia histórica (pp. 60-76). Buenos Aires: Alianza; FLACSO; Georg Eckert Institut

Buletti, S. (2019) Apropiaciones docentes de materiales de divulgación histórica del Canal Encuentro. Tesis de Maestría en Historia Contemporánea, UNGS (inédita).

De Amézola, G (2015). La Historia latinoamericana en la escuela argentina de hoy: rupturas y continuidades. En Zamboni, E.; Galzerani, M. y Pacievitch, C. (orgs.), Memória, sensibilidades e saberes (pp. 244-260). Campinas, SP: Alinea.

De Amézola, G. (2011). Historia enseñada e historia investigada: relaciones peligrosas. El tratamiento escolar de la última dictadura militar y la necesidad de una actualización académica en la formación de profesores. PolHis, Año 4, $n^{\circ} 8$. Recuperado de: http://polhis.com.ar/datos/polhis8 deAMEZOLA.pdf

De Amézola, G. (2008). Esquizohistoria. La historia que se enseña en la escuela, la que interesa a los historiadores y un cambio posible de la historia escolar. Buenos Aires: Libros del Zorzal.

De Amézola, G. (2006). Cambiar la historia. Manuales escolares, curriculum y enseñanza de la historia desde la transformación educativa. En Kaufmann, Carolina (dir.), Dictadura y educación. Los textos escolares en la historia argentina reciente (pp. 227-271). Buenos Aires: Miño y Dávila.

De Amézola, G. et al (2012) La dictadura militar argentina en los manuales de Educación General Básica. En Kaufmann, C. (coord.) Textos escolares, dictaduras y 


\section{¿Qué llega de la historiografía académica a la historiografía escolar? Una exploración en torno a la temática de la última dictadura en la escuela secundaria}

después. Miradas desde Argentina, Alemania, Brasil, España e Italia (pp. 103-134). Buenos Aires: Prometeo

Devoto, F. (1992) Idea de nación, inmigración y “cuestión social” en la historiograf匇 académica y en los libros de texto en Argentina (1912-1974). Estudios Sociales, n. 3, pp. 9-30.

Dicroce, C. \& Garriga, M. C. (2011). "Los textos y contextos en la enseñanza de la historia latinoamericana, 1983-2009”. En Bohoslavsky, E.; Geoghegan, E. y González, M. P (coords.). Los desafíos de investigar, enseñar y divulgar sobre América Latina. Actas del taller de reflexión TRAMA. Los Polvorines: Ediciones UNGS. Recuperado de:

https://www.ungs.edu.ar/cm/uploaded files/file/publicaciones/trama/dicroce.ht $\underline{\mathrm{ml}}$

Duhalde, E. (1999 [1984]). El Estado terrorista argentino. Quince años después, una mirada crítica. Buenos Aires: Eudeba.

Feierstein, D. (2007) El genocidio como práctica social. Buenos Aires: Fondo de Cultura Económica.

Finocchio, S. (1989). Programas y textos en la historia de cuatro asignaturas de la escuela media: Historia, Lengua y Literatura, Educación C国ica y Fisica. Propuesta Educativa, año 1, no 1, 51- 63.

Finocchio, S. (1991). ¿Qué llega de nuestra investigación a la escuela media? Entrepasados. Revista de Historia, 1, 93-106.

Finocchio, S. (1999). Cambios en la enseñanza de la historia: la transformación argentina. Revista Iber. Didáctica de las Ciencias Sociales, Geografía e Historia, 22, 1730.

Finocchio, S. (2007). Entradas educativas a los lugares de la memoria. En Franco, M

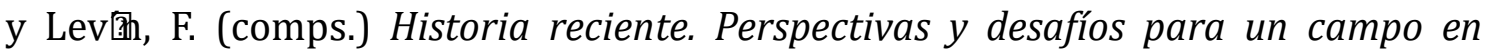
construcción (pp. 253-277). Buenos Aires: Paidós.

Franco, M. (2018). La última dictadura argentina en el centro de los debates y las tensiones historiográficas recientes. Tempo e Argumento, 10, 23, pp. 138-166, Florianópolis.

Franco, M. (2016) La noción de “dictadura c⿴囗玉ico-militar". En Flier, P. (coord.) Mesas de debate de las VII Jornadas de Trabajo sobre Historia Reciente. La Plata: Ediciones UNLP. 


\section{María Paula González}

Franco, M. (2012). Un enemigo para la nación. Orden interno, violencia y "subversión". 1973-1976. Buenos Aires: Fondo de Cultura Económica.

Franco, M. \& Iglesias, M. (2011). El estado de excepción en Uruguay y Argentina. Reflexiones teóricas, históricas e historiográficas. Revista de História Comparada, Vol. 5, №. 1, pp. 91-115.

Franco, M. \& Lvovich, D. (2017). Historia Reciente: apuntes sobre un campo de investigación en expansión. Boletín Del Instituto De Historia Argentina Y Americana "Dr. Emilio Ravignani", 47, pp. 190-217.

González, M. P. (2019). Para una historia de la historia argentina reciente en la escuela: inclusiones, dilemas, transformaciones y desafß̧乃s (1979-2018) Revista Avances del Cesor, ISHIR-Conicet, vol. $16 \mathrm{n}^{\circ}$ 21, pp. 105-125. Recuperado de: http://web2.rosario-conicet.gov.ar/ojs/index.php/AvancesCesor/index

González, M.P. (2018). La enseñanza de la historia en el siglo XXI. Saberes y prácticas. Los Polvorines: Ediciones UNGS.

González, M. P. (2014). La historia argentina reciente en la escuela. Saberes y prácticas docentes en torno a la última dictadura. Los Polvorines: Ediciones UNGS.

Lanza, H. (1993). La propuesta oficial y la propuesta editorial para la enseñanza de la historia en la escuela media. En Lanza, H y Finocchio, S., Curriculum presente, ciencia ausente. Tomo III La enseñanza de la historia en la Argentina de hoy (pp. 1795). Buenos Aires: FLACSO-CIID-Miño y Dávila.

Le Goff, J. (2016) ¿Realmente es necesario cortar la historia en rebanadas? Buenos Aires: Fondo de Cultura Económica.

Lewkowicz, M. \& Rodr屏uez, M. (2016). Historiograf通 académica e historia escolar. Los libros de texto de historia entre dos centenarios. História da historiografia: International Journal of Theory And History Of Historiography, n. 20, pp. 48-68. Recuperado de: https://www.historiadahistoriografia.com.br/revista/article/view/977/618

Montero, A. (2016) El objeto discursivo ‘dictadura c⿴囗玉 reciente: narrativas históricas y sentidos contemporáneos. Crítica Contemporánea, 6, pp. 53-77. Recuperado de: https://www.colibri.udelar.edu.uy/jspui/bitstream/20.500.12008/9115/1/CC Mo ntero 2016n6.pdf

Oberti, A. \& Pittaluga, R. (2016) Apuntes para una discusión sobre la memoria y la pol团ica de los años 60/70 a partir de algunas intervenciones recientes. 


\section{¿Qué llega de la historiografía académica a la historiografía escolar? Una exploración en torno a la temática de la última dictadura en la escuela secundaria}

Sociohistórica

e015.

Recuperado

de:

http://www.sociohistorica.fahce.unlp.edu.ar/article/view/SH015

Pittaluga, R. (2010) Pasado reciente argentino. Interrogaciones en torno a dos problemáticas. En Bohoslavsky, E. et al (comps.) Problemas de historia reciente del Cono Sur (pp. 23-35, tomo I). Buenos Aires: Prometeo-UNGS.

Reta, M. y Pescader, C. (2002). Representaciones del pasado reciente. Análisis de los textos escolares de nivel medio. Clío \& Asociados. La Historia Enseñada, 6, 50-70. Recuperado

de: https://bibliotecavirtual.unl.edu.ar/publicaciones/index.php/ClioyAsociados/artic le/view/1568/2482

Romero, L (1994). Breve historia contemporánea de la Argentina. Buenos Aires: Fondo de Cultura Económica.

Romero, L (2012). Breve historia contemporánea de la Argentina (1916-2010). Buenos Aires: Fondo de Cultura Económica.

Romero, L. (coord.) (2004) La Argentina en la escuela. La idea de nación en los textos escolares. Buenos Aires: Siglo XXI.

Sigal, S. (2001). La polémica sobre el genocidio. Revista Puentes, 2, 5, pp. 62-65. La Plata: Comisión Provincial por la Memoria.

Valls, R. (2012) Historiografía escolar española: siglos XIX-XXI. Madrid: UNED.

Vezzetti, H. (2002). Pasado y Presente. Guerra, dictadura y sociedad en la Argentina. Buenos Aires: Siglo XXI.

Zysman, N. (2015). De la subversión marxista al terrorismo de Estado. Representaciones de la última dictadura militar en las narrativas históricas de la

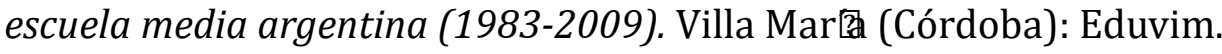

\section{Fuentes curriculares}

ME (2012). Ministerio de Educación. Núcleos de Aprendizajes Prioritarios. Ciencias Sociales. Campo de formación general del ciclo orientado de Educación Secundaria. Buenos Aires: Publicaciones del Consejo Federal de Educación.

ME (2011a). Ministerio de Educación. Núcleos de Aprendizajes Prioritarios. Ciencias Sociales. Ciclo básico de Educación Secundaria. Buenos Aires: Publicaciones del Consejo Federal de Educación 


\section{María Paula González}

MECyT (2006) Ministerio de Educación, Ciencia y Tecnolog龟. Núcleos de Aprendizajes Prioritarios Ciencias Sociales. EGB/Nivel Medio 8/1 y 9/2 años. Buenos Aires: Publicaciones del Consejo Federal de Educación

PBA-DGCyE (2005). Provincia de Buenos Aires, Dirección General de Cultura y Educación. Programa de Definición del Diseño Curricular del Nivel Polimodal de Espacio Curricular Historia. La Plata: Publicaciones de la DGCyE.

PBA-DGCyE (2011). Provincia de Buenos Aires, Dirección General de Cultura y Educación. Historia, 5to año. Escuela Secundaria Orientada Ciclo Superior, Ciencias Sociales. La Plata: Publicaciones de la DGCyE.

PBA-DGCyE (2012). Provincia de Buenos Aires, Dirección General de Cultura y Educación. Historia, 6to año. Escuela Secundaria Orientada Ciclo Superior, Ciencias Sociales. La Plata: Publicaciones de la DGCyE.

\section{Materiales didácticos}

Aique (2013) Historia argentina. 1976 - 2013. Proyectos de país en pugna: de la última dictadura cívico-militar al kirchnerismo. M. Ernestina Alonso, Enrique Vázquez. Buenos Aires: Aique.

Aique (2000) Historia Argentina Contemporánea (1852-1999). M. Ernestina Alonso, Enrique Vázquez. Buenos Aires: Aique.

Estrada (2011) Historia 5ES: La segunda mitad del siglo XX. Mar鱼 Inés Tato [et. Al.]. 1a ed.- San Isidro: Estrada.

Kapelusz (2013) Historia de la Argentina, Mariana Pérez... [et. Al.] 1a ed.- Buenos Aires: Kapelusz.

Maipue (2012) Historia VI. Historia reciente en Argentina. Teresa Eggers-Brass. 1aㅗ ed.- Buenos Aires: Maipue.

ME (2010). Ministerio de Educación. Programa Educación y Memoria. Pensar la dictadura: terrorismo de Estado en Argentina. Problemas, respuestas y propuesta para su enseñanza. Buenos Aires: Publicaciones del Ministerio de Educación.

ME (2011b). Ministerio de Educación. Programa Educación y Memoria. A treinta y cinco años del golpe, educación y memoria. Cuadernillo para secundaria. Buenos Aires: Publicaciones del Ministerio de Educación.

Santillana (2017). Historia: Argentina y el mundo: la segunda mitad del siglo XX. Nuevos Saberes clave. Andrea Andújar... [et. Al.] 1a ed. Buenos Aires: Santillana. 
¿Qué llega de la historiografía académica a la historiografía escolar? Una exploración en torno a la temática de la última dictadura en la escuela secundaria

Santillana (2011). Historia: Argentina y el mundo: la segunda mitad del siglo XX. Saberes clave. Andrea Andújar... [et. Al.] 1ํㅡ ed. $2^{\underline{a}}$ reimp. Buenos Aires: Santillana.

Recibido: 30/07/2020

Evaluado: 22/09/2020

Versión Final: 14/10/2020 